\title{
Maintaining the Connection: Strategic Approaches to Keeping the Link between Initiating Congregations and Their Social Service Off-Spring
}

\author{
Ian Bedford 1,2 \\ 1 St Stephen's Uniting Church, PO Box 189, Wodonga, VIC 3689, Australia; ianjudybedford@iinet.net.au; \\ Tel.: +61-26-056-0524 \\ 2 Formerly faculty of Albury-Wodonoga Campus, Latrobe University, Melbourne, VIC 3086, Australia
}

Academic Editors: Peter Kaufman and Robert Wineburg

Received: 7 March 2016; Accepted: 19 August 2016; Published: 25 August 2016

\begin{abstract}
Whilst much research has established that religious congregations have a long history of initiating social services that address many and varied community welfare and health issues, little attention has been paid to the process involved in this congregationally-based response as well as little paid to the unique issues that arise such as the role of clergy in their development and operation. Some research has however identified examples of congregationally-initiated programs evolving to the point where their link to their initiating congregation becomes effectively severed. The research reported in this article is drawn from a larger research project that identified a framework for understanding the complex processes by which congregations initiate, operate, and modify their social services. However, it focuses in particular on the resources such congregations can bring to a wider community and the need for intentional strategies to address the risk that such resources may be lost if the link to the congregation is allowed to atrophy. Whilst the more comprehensive framework focuses on an integrated understanding, this article gives specific attention to those issues and strategies relevant to maintaining the link where that is the implicit expectation of the congregation rather than taking it for granted and being surprised when it is found to have gone.
\end{abstract}

Keywords: congregations; social service; ownership

\section{Introduction}

It was in the 1980s that Wineburg [1-3] began to notice a pattern occurring in his community as a response to the US Federal Government reduction in funding for community social services; this was one of steady growth in the participation of religious congregations in the local provision of social services. This pattern became a growing focus of significant US research on the extent and nature of these emerging (and pre-existing) congregationally-based social services, with some key researchers being Wineburg [4] in Greensboro NC, Dudley [5] in Chicago IL, Farnsley [6] in Indianapolis IN, Cnaan [7] in Philadelphia PA and Chaves [8]. In the United Kingdom (UK), Harris [9] in particular noted a similar involvement of religious congregations in what she termed the provision of "Quiet Care" to their local communities, whilst in Australia Kaldor and his colleagues [10,11] associated with their National Church Life Surveys of 1991 and 1996, began to document a similar response to community needs by church congregations.

Much of this research focused on documenting the extent to which congregations engaged in this type of social response, the nature and replacement dollar value of the resources they offered, and the type of services that were provided to the community by these means. However, almost as an aside to this focus, Harris commented in her work that: 
Paradoxically, the ultimate 'success' — of having a project adopted by an outside funder in the government or voluntary sector-was often regarded as a mixed blessing by congregations. Whilst they were glad to be relieved of constant anxiety about finding financial and human resources, they also resented their loss of control and were anxious about being pulled in to a more formal caring world...The affiliation brought essential contacts and expertise into the group but also created pressures to professionalization and formality. Additional...questions were raised about the extent to which [the activity] was still a congregational [italics in original] project ([12], p. 167)...Even though such sponsorship reflects project success and offers the possibility of expansion with less responsibility, it may take from the volunteers what they most value: the ability to control the project and run it according to their own preferences ([12], p. 169).

In like terms, Cnaan and colleagues included the following comment:

[P]eople in the congregational camp are worried about the impact that such collaboration with government may have on the congregation as a place of worship. It is possible congregations will be forced to apply practices that are not well accepted by members and that will impinge on their religious freedom and sense of being. The experience of transforming volunteer programs into professional and paid ones is often accompanied by increased bureaucratization...and stagnation...[T] he spirit of volunteerism and enthusiasm in congregations may subside when some members are paid for the work that others formerly provided voluntarily...tensions may build between paid staff and the traditional volunteers, and the volunteers may withdraw ([13], p. 7f).

Both researchers identified that, in regard to their case samples, "something" was at risk of being lost when congregationally-based social services begun as a response to their faith perspective become entwined with the processes of government and other external funding. That something, Harris suggests, is "control" whilst Cnaan suggests it is "the spirit of volunteerism".

My own practice experience as a social worker in two Australian States, Victoria and Queensland, led me to ask questions not so much about the nature and extent of this congregationally-based social service provision, but the intrinsic processes by which these services were developed and sustained. This stimulus for research led to a doctoral study [14]. The data obtained, provided a detailed overview of factors involved in Initiating, Operating, and Modifying congregational community services. Initiation included Congregational Culture, Key Persons and Catalysts coalescing to generate a Vision for social service. Operations included Programming, Staffing, Resourcing, Managing, Networking, Owning, and finally Modifying. The modifications examined social services, agency, and program development. Thus a need arose to examine Evaluations, Crucial Decisions, and Unexpected Events. The overall thrust of this deep internal process analysis, is remarkably consistent with the later research of Garland and her colleagues [15] when researching How 35 Congregations Launched and Sustained Community Ministries. However, their article focuses on the "factors" in congregational "support" for "community ministries." My research focused on the processes engaged in when developing and operating these social services.

The keys to my analysis are deciphering the processes by which congregations linked their social capital to the provision of social services, and coupling them to their wider community. Here I was able to decipher the patterns by which that linkage could be undermined. This analysis therefore was consistent with the concerns noted by Harris and Cnaan, as well as in many a history of the provision of social services initiated from congregational settings, for example as touched on in the article in this volume by Netting and $\mathrm{O}^{\prime}$ Connor [16]. As such this research suggests that the factor at risk of submergence is losing the emotional "Ownership" by a congregation of their social service activities.

This paralleled Harris' sense of the "control issue" (congregation or community) as well as Cnann's sense of the importance of maintaining volunteer spirit. Further, my analysis maintains that the loss of spirit can be prevented. It is the purpose of this article to outline the contribution 
congregations can bring to the provision of community services and keep them from losing their voluntary spirit. After reflecting from that, the article will elaborate on the strategic options that the research on the identified congregations used to maintain their linkage with the social services they spawned and thus kept in part their emotional and psychological "Ownership". It must be remembered that, being a first of its kind research, I was generalizing and will be generalizing to theory grounded in this analysis.

\section{Research Method}

This research was undertaken in Victoria, Australia, following a qualitative methodology and applying a "grounded theory" research design [17]. Data consisted of four datasets sequentially collected along the Theoretical Sampling approach of Grounded Theory. The first dataset consisted of 13 in-depth, unstructured interviews with social workers who had worked and volunteered in many and varied ways at the "local church—social service agency" interface. The second data set was obtained through similar in-depth, unstructured interviews with seven people from a congregation in a low-income, largely public housing area of a provincial city (Congregation A), whilst the third dataset was similarly obtained from eight people involved with the social service activities of a congregation located in a largely upper middle class suburb of a metropolitan city (Congregation B). The fourth dataset was obtained from 24 documents longitudinally generated over a 10 year period along with one in-depth interview with the congregation minister of a congregational social service located in a low-income, multicultural suburb of the same metropolitan city (Congregation C). All interviews were transcribed and provided back to interviewees for correction and final permission to use in a progressive thematic analysis as called for in the Grounded Theory approach to coding of data and the identification of "theoretical saturation" for emerging concepts. Coding was undertaken using the software QSR NVivo 1.3.

\section{Results}

One of the six dimensions identified for the way in which congregations operated their social service activities was labeled "Owning", the last dimension of operation to emerge from or be identified through the iterative data analysis process that is characteristic of the Grounded Theory approach. This dimension was identified through statements from respondents such as:

Well I really want [the congregational council] to own the decision where we go [with regard to the future of the Community Service activity]. I don't believe it's the [Parson's] decision to head off in a certain direction [such as separate Incorporation] because ultimately...the longer they've been here the closer they are to going somewhere else...I think the [congregational council] have to own the decision [about] which way we are going...what we've got to do to pay our bills and all those sorts of things...three people shouldn't be worrying themselves sick at night about everything [18].

In reality it is a fascinating thing, the issue of ownership...There's a core group who believe in [the community service]. The [congregation] has, as the year progresses, more and more accepted [it] as being a ministry within the congregation, there to stay [19].

I think unless [congregational community services] enlist the active support of lay-people who take ownership then these activities...[are] fragile organisations, or organisms, subject to the priorities and gifts and self-esteem of the incoming clergy [20].

It is important to help [the Community Centre] struggle with this issue [of ownership]...If [the congregation] does not "own" the program, it "disowns" the program...Within the [Congregation], ownership has two strong foci of expression - in the clergy and in the volunteers. The [congregation] and the [congregational council] have still to come to terms 
with its existence, and some still view the [Community Centre] as a "[partner Agency] intrusion" into their program [21].

This term "ownership" clearly was seen as important in the process of operation.

\subsection{The Social Capital Congregations Provide to Their Linked Social Services}

What was clearly evident was that congregants who developed social services linked to congregations were adept at using the inherent social capital, as they knew it. Schneider explored this kind of social capital regarding congregation and community, quite thoroughly [22]. The characteristics of this social capital, or how program developers connected with people, to access resources, related, for example to the use of buildings, or tapping a source for help with staffing. Their use of agency board members to help get access to funding kept the link with a supportive community strong. In capturing social capital this way, they could maintain a spiritual base or context from which to function, and still claim ownership. These ideas warrant further elaboration.

\subsubsection{Buildings}

The most obvious resource that congregations provide in their development of social services is the use of their space to operate programs at no cost. However, this resource provision was not found to be as simple as might first be presumed in that there was a rather consistent evolution of the way this space was provided for the social service work.

Congregations typically have facilities where they meet for worship and other faith-related activities. These are then made available, so it seemed, to any social service that a congregation developed; typically at no charge (unless a partner church agency was paying, as applied in one of the research congregations). Rarely was the space actually suitable for the social service purpose to which it was being put. A main reason was that the ideas for the facility were not co-linked to the ideas for the program. Thus typically, the available facility was on a "take it as you find it" basis, but the research identified that, commonly, over time two typical changes happened.

Firstly, congregations became concerned about the unsuitable accommodation being provided for their social services and began to find ways to access funds to renovate them. Funds might be gained from special building appeals for the purpose, bequests becoming available, and grants from central church property funding bodies. These funds were initially used to make "modest" alterations to the facilities to provide a social service space more consistent with the service being provided, e.g., a shed built in the church yard from which an Emergency Relief service can operate and where recipients can be congenially welcomed as well as food etc. stored. Gradual purpose-specific changes helped create an overall sense that the social service is valued within the congregation as well as the wider community and is "improving" the way that service is delivered.

However, the second development, which is much more evident in the research congregations than might be casually expected, given overall funding issues, (see Section 3.1.3 below), is the remodeling of the congregational facilities to co-locate both worship space and general community space, which included the social service. All congregations saw a clear statement in this more extensive and expensive remodeling that their social service involvement was an explicit component of their faith understanding and commitment and a deliberate expression of it. Worship and service were integrated aspects of their identity as a faith community, and there was legitimacy in any who come for the support of the social service being at least visually aware that this service was integral in this way. That so many congregations gradually and eventually made this adjustment so intentionally was one of the key insights that this research brought into focus. Finding sufficient funds for such activities is no mean feat. One of the three congregations in this study went into significant, and at times, worrisome debt. Blending service into their spiritual life took form in expansion of the facility. While sometimes such expansions may be missed in a research article, I saw much tenacity from congregational leaders. Such rebuilding projects do not happen quickly or easily. So, to keep "ownership", congregants expanded their social capital skills to meet capital need too. 


\subsubsection{Staff and Board}

Analysis of the datasets identified four key areas in which social service staff were potentially engaged from within a congregation and/or its network of links to the wider church. These included both trained and untrained staff able to operate as "support workers" who provided reception, administration, and basic contact roles e.g., serving in an "Opportunity Shop"1. However, congregants often had minimal if any training for the role, and were typically volunteers. Some were very poorly remunerated for the time put in e.g., paid a small honorarium. At times they were officially employed but they also contributed many "volunteer" hours to the service in addition to paid hours. Most of the time, these people would comment that they were both giving and receiving from their involvement. Personal gains cited were enhanced social contact, better organization for their own daily routine, gaining referral information needed for personal reasons, sometimes quite similar to other users of the service. Most important for this article was an expression that such giving brought depth to their own faith understanding.

Other staff had more defined roles that required some degree of specialized contact with social service recipients, but often these volunteer personnel were given little if any training for their role e.g., as Emergency Relief service interviewers, and likewise little support and supervision. At the time of the research, some efforts were being made within each of the research congregations to redress this "start up" oversight through, typically, in-house provision of some training sessions. Some of these contact volunteers also exhibited an initiative to privately seek training for their role in order to address their anxieties about undertaking these roles without proper training.

Further, at least two of the congregations exhibited an amazing capacity to attract qualified professional people in "good standing" with their professional bodies to provide highly specialized services as either direct contact workers who received no payment e.g., qualified grief and loss counsellors, or as supervisors and consultants either for no or very minimal payment. In addition, professional staff were employed under award conditions but typically worked many hours longer than their award provisions. Some of these paid staff were also active members of the congregation and saw an overlap between their paid work and their ministry as congregational members. Such an overlap was found to sometimes cause role confusion and burnout. Others did not have that congregational link but shared the faith link and saw their work as part of the wider church ministry. Some employees had no such identification with congregation or faith and viewed their role as their professional employment.

Finally, there were the clergy themselves. They often took on a range of roles within the social services. Sometimes they were the key contact person whose work and ministry were supported by the others from the congregation and community. One minister in the study undertook a self-appointed role as community caseworker for people with mental health issues.

Sometimes clergy took on the role of de facto Chief Executive Officer for the social service, overseeing its overall functioning and administration. They would combine that role with chair of any board or committee nominally responsible for overseeing the social service. In some situations, the clergy acted as community workers undertaking a variety of roles such as local school chaplain, but seeking affirmation and support in that role from their congregation. In all these settings, it appeared to be the clergy who either were operating according to their own sense of social service ministry but with varying degrees of congregational support, or who had brought a particular vision of social service to a congregation and gained their commitment to support and share in that social service ministry or ministries.

In contrast, some clergy recognized the social service concerns of congregational members, recognized the skills and interests of the congregation, and then worked to encourage and support the

1 A program of two congregations in the study which sells secondhand clothing and household items at very low cost affordable to low-income people. 
sense of social service ministry of these congregations. They might function as supervisors, it might be as limited back-up contact support, or it might be as an active member of the board or committee overseeing the social service. Two things were evident in regard to the clergy role. Firstly, where the motivation and or direction came from the clergy, there was an evident fragility about the longer term viability of the social services that developed for they were heavily dependent on the energy of these clergy. This friction came to be because the clergy may have been perceived as focusing more on the services than the congregation's needs. Secondly, the capacity of congregational members to sustain their individual and collective involvement was enhanced significantly when clergy were active permission givers and encouragers of congregational involvement as opposed to passive accepters or even "benign" neglecters of that involvement. This interdependence of congregational involvement and even initiative with clergy's active permission by giving and encouraging was another of the unexpected key insights arising from this research. The clergy member leading from behind seemed to be the healthiest leader for the whole congregation and community.

Congregations also often provided the people who had some sort of formal oversight of the congregational community services. This might be a responsibility of the overall congregational board or council, with a social service as but one area of their oversight e.g., the oversight of a congregation's community Opportunity Shop. This might be the "official" position, with little more than tacit attention paid to it, but with an informal cluster of congregational people who chat among themselves on an "as need" basis maintaining some oversight, or it might be a semi-formal "committee" that meets semi-regularly providing that oversight. Increasingly, congregations were discovering that informal ways of operating were likely to be legal risks.

Hence, some instituted formal incorporation as legally separate bodies but with boards made up of at least a majority of congregational members, if not fully of congregational members. Being legally independent did not necessarily break the nexus with the congregation, although the risk of that is a matter requiring consideration. The legal alternative was for the social service to be merged with a larger church social service established legally in other ways, but sharing with the congregation an agreement for mutual engagement in the congregation's geographical area. One of the research congregations had a formal agreement to that effect, with a condition that neither party could unilaterally withdraw from the arrangement but had to engage in a mutual negotiation to address any issue and respond as jointly agreed. In the event, this central church agency provided financial management and overall management support but left the congregationally based personnel to determine the exact social service programs on offer.

Leadership of board and social services was sometimes undertaken by the clergy. In fact, a unique feature of congregational community service development was the availability of clergy as lead personnel in a way other community-based social services could not expect to have, a special resource for effective social service development. However, at times the qualified personnel already identified with a congregation would take on these formal leadership roles, often contributing significant expertise including legal advisers, treasurers, program supervisors, and management consultants. In some settings it was recognized that congregations could support the formal training and professional development of needed leadership personnel and staff by intentionally calling members to these social service ministries and facilitating their development.

Overall, what was evident was a significant capacity of congregations to staff social services they began, albeit sometimes naively at first, but often with a high level of experience and competence as well. This may lead to some dubious "in house" appointments but, conversely, may also facilitate a shared commitment to the social services in question. Above all, however, this arrangement was clearly associated with a significantly less than "commercial" salary cost being needed to sustain the social service. Nonetheless, there were a range of risks associated with this arrangement including burnout, lack of adequate training, and lack of supervision. 


\subsubsection{Funding}

Because of the facilities and staffing options potentially available to congregations (i.e., facilities typically provided rent-free and staff either unpaid volunteers or paid only small honorariums), operating costs are likewise potentially lower than might otherwise be encountered when establishing and operating a social service based on a more typically professionalized basis. Indeed, two of the three congregations included in this research appeared to have relatively low costs for these reasons using mainly volunteers, including professionally accredited volunteers. The third congregation, even though facing higher costs in some areas of its social service due to employing a small number of key professional staff, was still the clear beneficiary of these unfunded contributions from their associated congregations (i.e., encountering low or no rental costs and other professional staff being volunteers as well as volunteer support staff).

Congregations have a culture of giving, in contrast to the philanthropic responses of Australians generally [23]. However, all three research congregations found that regular direct giving by congregational members to their social service activities was far short of what was needed, despite some concerted fundraising efforts being evident. Many costs were apparently "absorbed" into the general congregational operating budget (e.g., wage contribution of the clergy, utilities costs, office space nominal rental charges, photocopying) with no recognition whatsoever of this income forgone by the congregation, income needing to be "replaced" if the social service was to operate outside of a congregational setting. Nonetheless, there were direct congregational contributions such as the salary of a paid Director/Coordinator of a social service. These contributions were in fact never sufficient and the shortfall, where it existed, was addressed by a range of other means: applications for grants from wider church funds, applications for grants from community philanthropic sources, applications to larger central church agencies for funds, applications to local government for community funds, fundraising initiatives such as special social events and income producing Opportunity Shops or fee for service activities, and, significantly, contracts with government to deliver certain services.

This plethora of funding sources was found to have two serious dilemmas. Firstly, the largely ad hoc sources offered no guarantee of continuity, meaning the funding of these social services was always uncertain and unreliable. For example, philanthropic trusts might give a significant grant once, and then not consider the social service for another few years. Grants from Central Church sources were typically more predictable than that, but always uncertain and dependent on funding policies. In-house fundraising sources such as Opportunity Shops or, in one case, a Calendar publishing enterprise, were more reliable but still limited in their contributions. The second dilemma was the administrative detail and time required to seek grants from philanthropic bodies, and more especially government, combined with the commitment to operate any program so funded, but with an expectation that the funds provided would not fully meet operating costs. Those who went this path reported significant stress whilst undertaking the formalities involved. Government funding was also found to compromise the social service agendas of the churches and congregations concerned with service agendas becoming defined by personnel outside the actual service delivery contexts.

Overall, it was clear that congregations, to the extent that funding is needed for a social service, can access such funding from somewhat novel sources, but the pattern was clearly one that evidenced a perpetual inadequacy of funding to meet the developing needs of these social services, even when such funding is derived from government contract. If the "full cost" of operating these services was taken into account, then these social services may well never survive. With so many costs effectively covered by default by congregations, then the constant round of fundraising apparently has proved to be barely "sufficient" at least for a time, even if unpredictable and administratively demanding.

\subsubsection{A Community of Support}

The significant set of resources for the provision of social services clearly have their origins in that sense of caring and social concern that is characteristic of at least some religious congregations. Within these congregations, that concern extends beyond the mere provision of a social service. It is 
evidently expressed in all the research congregations (and many others reviewed beyond those formally researched) to be a community of care readily accessible by any who seek such personal support. It is a community that actively exists and is therefore, apparently, available to some degree when needed. It is a community that has a value or ethic that readily adds supportive care of outsiders to its formal purpose for existing. It is a community willing to put its resources to use to provide such care and involvement.

However, congregations are not only willing to directly provide such resources, formally and informally, to the wider community; they are also apparently willing to tap into wider community resources to enhance their capacity to undertake these responses. The research congregations were found to tap into other congregations and resources within their own religious denomination even from outside their immediate area, the resources of religious congregations linked to other denominations, especially those existing within their own geographical area, and also the resources of like-minded people who have no religious affiliation or even identification if they are willing to be an active part of the congregational social service. In this congregations become facilitators or catalysts for a wider and more integrated resource of care within a community.

Further, whilst many of the social services are formal programs such as Emergency Relief provision or Grief and Loss Counselling, what all the research congregations did was develop ways which help promote a less formal means of social inclusion and informal interpersonal care. This resource, then, was evidently a dimension of community care not readily accessible in social services that operate in formal and professionalized settings. It was also a natural and integrated setting, not a social group formed of people with a common social limitation.

These are achieved through Coffee and Chat activities, craft groups, as well as the general atmosphere of non-judgmental acceptance that typically accompanies these congregational social services. These informal strategies for accepting and supporting people in need, toward people who may have experienced some form of social alienation, are the therapeutic resource that a few of the social workers interviewed identified as a strength of congregational social services, their "magic" as one recently stated. For one respondent, it was a partnership possibility with the more formal and professional processes of a central church agency, whilst for another it was a natural outcome of the social service operating within the context of integration with a worshipping and caring community. The informal support sought was able to be obtained from a known community i.e., a community whose acceptance and caring response was a given and not something needing to be accessed without prior knowledge.

\subsubsection{A Spiritual Base}

Another, perhaps even more unique component of the resources a congregational social service can offer is a recognition of and response to the spiritual dimension of a service user's life and concerns. The discussion of spirituality in the helping professions and in social services is a potentially vexed issue and the debate around it is beyond this article. Rather, this study recognizes that for congregations, some understanding of their spiritual purpose in offering a social service is a component of what they offer. In some cases, this may involve an intentional strategy to share that spiritual perspective with those who make use of the service.

This approach is likely to raise many issues of concern which were grappled with in one of the research congregations, at least until congregants realized through their discussions that this was not really a core aspect of their purpose in providing the service. Rather, they joined the other congregations in seeking only that they operate in a manner consistent with their spiritual basis and be able to share that with service users should there be any who wish to engage with that aspect of their lives.

Within the social work profession, it has been recognized that spirituality is a potentially legitimate component of some people's lives and concerns [24,25]. Hence, it was recognized by some respondents that a congregational social service that was potentially willing and able to respond to that at some level 
was a valuable community resource not typically available in other settings. Such a congregational setting, by its very nature, would give clear permission for service users, concerned about that aspect of their life and concerns, to seek a response at the spiritual level. Such responses indeed had no place for being imposed on people any more than it was supportive to deny concerned people access to them. Congregational community services therefore provide a natural and accessible setting for this dimension of life to be incorporated as appropriate for any given service user.

Further, congregational community services also readily "undergird" their community service with their spiritual life. It perhaps is rather obvious to say that the very existence of a congregational social service reflects in some measure the activation of the spiritual resources of a congregation. However, in many congregations these more obvious and concrete resources are reinforced by further "quiet" spiritual resources such as praying for those who come into the facility, a readiness to engage in more spiritual processes should they be sought, as well as a potential willingness to advocate for issues of social concern and justice of which any particular service user's issue might be an example. These are the sort of value-added components that congregational social services can generate.

\subsection{An Observed Pattern of Development Potentially Leading to Disconnection}

This pattern in the analysis of congregations engaging in social service delivery in their community, whilst based on a small sample yet consistent with casual observation of past and present congregational activities, provides a good insight into key facets, and levels of detail not yet chronicled of congregations evolving into service providers. Whilst evidence from this study is emerging to point out that the processes are complex, some features reflect a basic volunteer mentality of "making do," whilst other aspects feature an increasingly formal and structured approach. However, this data also suggest that there are strengths in both. What is instructive is that the unexpected combinations of these two features are much more reflective of the processes involved.

Yet the data also suggests that, without an awareness of the intricacies of this process, there is an inherent risk that these social services tend to evolve towards what is labelled a default outcome. The loss of congregational connection and a growth of formality is something that most congregations cannot manage. Here in Australia, the history of development of congregationally initiated programs such as those listed in the Uniting Church report, Rejoining Word and Deed [26], suggests that most congregations that develop social services effectively lose their congregational connection in all but name, unless a deliberate strategy is adopted to ensure that links are maintained. Such is the case even as programs are improved to meet best practice requirements. The pattern for the operation emerging from this research identified not only what congregations offer the community by way of social service resources, but also an understanding of how to manage this evolution strategically.

The default pattern has been identified by a social work respondent as one which involves the appointment of people to key roles in a congregational social service such as a Chief Executive Officer or a Professional Social Worker. This pattern is identified as:

(1) In order to secure government funding and/or to meet formal funding requirements, congregational social services seek to appoint suitably qualified personnel who are either active members of the congregation or who are willing to move to the congregation's locality and become active members of the congregation;

(2) If such persons are not available, congregational social services seek to appoint suitably qualified persons who, whilst not living locally and/or not members of the congregation offering the social service, identify with the faith perspective of the congregation and endorse it;

(3) If such persons are not available, congregational social services then seek to appoint suitably qualified persons who agree to abide by the values and ethos of the congregational perspective and social service goals even though not personally engaging with the faith perspective that generates them. 
This process is, of course, not the totality of complex issues that can move a congregational social service from one in which the blend of creative, if sometimes naïve, volunteerism and a growth of professional formality can steadily move the social service away from its congregational intention to that of a professionalized and secularized church sponsored agency with little but an historical link to its founding congregation. However, in order to maximize the retention of those qualities that are indeed constructively available through the congregational setting whilst obviating aspects that risk the provision of a quality social service, a strategic approach that intentionally counter-balances volunteer features with professional features is called for. Within this approach there is a need to be strategic about maintaining the congregational link rather than taking it for granted as it in fact steadily dissipates with further developments occurring along the lines of the processes outlined above.

The remainder of this article outlines those strategies which were identified in the research as potentially contributing to a goal of retaining the strengths of the congregational link even as other developments occur. This can be summed up in the concept originally mentioned, referring to approaches that promote a retention of the congregation's sense of emotional and spiritual ownership.

\subsection{Strategies That Work to Maintain the Connection}

As congregationally linked social services developed, it was apparent that the link was typically taken for granted. What gave substance to that link was neither recognized nor sought. However, as presumed features of that link dissipated, congregational members would begin to express concerns that reflected their awareness that things were changing even if they could not quite name them specifically. Further analysis of comments in the datasets reflect this recognition. When examined further, I identified a range of actions which were seen to help promote a sense of "ownership" or linkage. Such actions were recognized through their decline or omission rather than as intentional ways to promote congregational social services. Once recognized, these become a list of potential strategies which could be intentionally implemented to build and sustain this congregational link.

These are:

- the emergence of a congregational vision that explicitly incorporates a specific social service as a component of congregational life and mission;

- formal structures of some sort between the congregation and the social service which indicate how the congregation will operate their social service whilst retaining the congregational link and responsibility;

- participation by congregational members in the defined decision-making structures related to the social service as board/committee members;

- announcements about the social service activities, needs, and progress made during the congregational community notices and/or weekly information sheet as part of each worship service along with a promotion of the link through congregational teaching in sermons which maintain an awareness of and reinforce congregational engagement;

- financial contributions to and fundraising for the social service as a part of the congregational budget arrangements along with some involvement by the congregational administrative and/or mission personnel in the social service's own budgeting processes;

- a logo for the social service that explicitly articulates the congregational linkage with the social service included on all notice boards and church publications;

- provision of a pool of congregational volunteers to work within the social service as their ministry contribution to the congregational mission;

- staff for the social service being appointed from within the congregation as the ministry involvement of these qualified personnel;

- general congregational participation in the activities of the social service e.g., as participants in the craft group established for people with mental health issues or volunteers organized to provide the refreshments for a Coffee and Chat activity for users of the social service; 
- congregational provision of buildings that meet the need of the social service, especially ones that have been redesigned to address the social service focus;

- prayer support for the work of the social service to express the faith perspective that the social service is indeed a ministry of the congregation.

This is a formidable list of actions exhibiting this link between social service and congregation. How many are crucial for such links to be seen as strong was not clear. What was clear was that, when a lack of such linking activities was seen to be growing, the sense of ownership slipped, leading to a further decline in the key resources accessed through the congregation itself. Further, as ownership slipped, it was sometimes identified with the development of a more significant and formal professional culture of operation consistent with Cnaan's loss of a spirit of volunteerism as well as Harris's loss of control. Hence, this analysis identified that respondents saw a need to intentionally promote congregational ownership and linkage by being intentional about these expressions of that link.

\subsection{Deterrents to Congregational Ownership Retention}

Whilst the relevance of the previously mentioned actions to maintaining the linkage between a congregation and its social service may be a belated recognition born of their subsequent absence, a number of respondents also noted a series of concerns that impact congregational social services, typically undermine the retention of a link regardless of where a congregation may be on these previous actions. Such influences are as follows:

- The complexity of fundraising was identified as a significant deterrent for congregational social services. These matters included the diversity and conditions of government and philanthropic funding requirements and sources. Such funders require the need for the retention of detailed records for programmatic expenditure, and the accountability requirements for reporting accurately on the utilization of funds received;

- The scale and complexity of current program delivery approaches involving complex management procedures to monitor and evaluate such programs including health and safety as well as risk management;

- The limited capacity in skills and personnel of a congregation to resource these management aspects of modern day social service delivery;

- The excessive dependence of congregational social services on retirees, women, and the unemployed for the personnel to staff congregational social services;

- The difficulties in providing adequate supervision and support for the staff that are found, whether paid of voluntary;

- The potential for burnout by highly motivated and committed staff who experience difficulty in drawing a boundary between their social service involvement and their general involvement in congregational life and ministry;

- The commitments of congregational members elsewhere than in social service delivery, such as family life, other aspects of congregational life, and their own work commitments;

- Lack of personal support for volunteers from key congregational leaders including clergy especially at crucial times such as illness;

- The inherent slowness to develop a specific program because of the series of meetings involved with doing so, or conversely the speed with which some leaders such as clergy, implement programs that reflect their agenda rather than an agenda the congregation feel able to resource.

Nonetheless, other respondents saw that these apparently increasing deterrents were simply matters that congregations committed to social service delivery could develop strategic means to address. These responses were evident in all three of the research congregations. These strategies, built into the operating processes of the congregational social services, included: 
- Establishing specific supervision and mentoring relationships with older people experienced in relevant aspects of congregational social services;

- Negotiating working partnerships with larger, more fully professionalized central church agencies able to offer administrative support such as with financial management and reporting, as well as with staff supervision and training relevant to the programs on offer;

- Ensuring that clergy recognize and respond with the necessary permissions and encouragements to support lay involvement and that they maintain a capacity and accountability to congregations with regard to their program visions and support for the program visions of congregational members;

- Strategically identifying that when actions are taken, such as to employ professional staff, the decision is made with intentional issues in mind. A relevant strategic purpose might reflect the importance of an appointment being actively linked to the congregational life and faith, or the importance of a position being a relevant blend of the less formal volunteer qualities of congregational culture as well as the more formal features of quality social service delivery;

- Ensuring that a congregation intentionally calls lay-people to and supports their training in the range of skills needed for the congregational social services including the knowledge, skills and formal professional recognition of key social service accreditation bodies;

- Maintaining due process when developing new social services and proper accountability processes when operating them, including seeking feedback from service users, congregational members, related community service providers, as well as use of a variety of evaluation strategies that assist service planning and development.

These responses from respondents all suggest that congregations can develop strategies to address potential deterrents where they are committed to the social services they set out to offer their wider community. The issue is one of being aware of the necessity of understanding the diverse complexities of the environment within which congregational social services operate and therefore the need for being intentionally strategic when considering their operation, rather than operating in a manner that just assumes a congregational link will remain. Without that strategic thinking, the risk is that gradually elements of the resources that the congregational link brings, the social capital that it offers, will be lost to the social service, a loss that formal and professional processes cannot in all aspects overcome. For example, loss of an informal community of support and the inherent responsiveness of socially connected congregations cannot be easily overcome through professionally facilitated client-focused support groups.

\section{Contextual Changes in the Past Decade}

Without undertaking a close examination of policy and procedural changes of the past decade, I have encountered two key changes impacting on congregations within the delivery of community services within the Australian setting. Firstly, government has moved substantially towards a so-called "Public-Private Partnership" approach which prioritizes contractually-based funding arrangements with large community service providers, both not-for-profit and for-profit. Secondly, the main religious denominations have engaged in a process of "merging" their locality-based community service agencies into single, large services able to compete in this new competitive, contractual environment (see for example the comments to a recent Synod of the Uniting Church in Australia [27]).

These two substantial changes appear to threaten the viability of the smaller, localized congregational community service activities that have come to depend on significant government funding. Whilst the central church bodies flag establishing alternative congregational support systems [27], nothing that supports local congregational involvement has yet clearly emerged. What is risked in the overall delivery of community services through these changes is the provision of low cost, high social capital engagement with at-risk people as these services professionalize and diminish the important sense of emotional ownership that is their hallmark. However, attention to the features 
raised in this article provides clarity for strategies aimed at assisting effective partnerships between congregations and these larger agencies which strategically value and nurture these links rather than diminish them.

Congregations which seek to maintain their own community ministry in the face of these changes will recall that, in the early years of congregational ministry before the gradual evolution of community services away from their founding congregation, congregations undertook their early work without government support. Conviction that community service ministries remain a crucial part of congregational life can therefore potentially see new forms of community ministry emerging in response to the "gaps" inevitably arising with these new Public-Private Partnership contracts. Once again, awareness of the concerns identified in this article provides clear strategies to support any such new developments.

\section{Conclusions}

Congregations in many instances have a strong history of developing social services for their wider community. History suggests many lose these services as they progress through a process of professionalization, secularization, and separated operation. In doing so, the congregations lose their community ministry as an expression of their faith, and social services lose a diverse range of social capital that otherwise supports their work and development. Whilst there may be an argument that congregations may well be good catalysts for social services that ultimately need to be taken up by the wider community and government, the research on which this article is based did not find that as the intention of any congregation. Support from government and community is welcome, but the retention of some sense of emotional ownership is assumed, and the loss of it contrary to congregational expectations.

This research has clearly established that this loss, this disconnect, is neither inevitable nor necessary. The findings call for strategic awareness of congregational community service processes. This is a balance between the congregational operating culture and that of a formal social service, which is regularly reviewed and changed. The findings indicate that congregations have significant social capital for a wider community social service provision. No formal, professional agency can ever fully replace that spirit of connection. For this reason at least, the link between congregations providing social services and their social service off-spring is one that continues to need strategic attention instead of an acceptance of an ad hoc default evolution that separates the two, the more so as more recent changes continue to develop and impact smaller congregational services.

Acknowledgments: The author was in receipt of an Australian Government Post-Graduate Research Scholarship whilst undertaking the research on which this article is based. No funding has been received from any source to assist with the publication of this article.

Author Contributions: The author is entirely and solely responsible for the totality of the research on which this article is based.

Conflicts of Interest: The author declares no conflict of interest. The author has had over 30 years of involvement as a congregational member, as a volunteer, and as a professional social worker in congregationally-based community services in Australia as well as spending nine years undertaking this research.

\section{References}

1. Robert J. Wineburg. "Volunteers in Service to their Community: Congregational Commitment to Helping the Needy." Journal of Volunteer Administration 9 (1990): 35-47.

2. Robert J. Wineburg. "A Community Study of the Ways Religious Congregations Support Individuals and the Local Human Services Network." Journal of Applied Social Science 15 (1991): 51-74.

3. Robert J. Wineburg. "Local Human Services Provision by Religious Congregations: A Community Analysis." Nonprofit and Voluntary Sector Quarterly 21 (1992): 107-18. [CrossRef]

4. Robert J. Wineburg. "An Investigation of Religious Support of Public and Private Agencies in One Community in an Era of Retrenchment." Journal of Community Practice 3 (1996): 35-56. [CrossRef] 
5. Carl S. Dudley. Basic Steps towards Community Ministry: Guidelines and Models in Action. Washington: Alban Institute, 1991.

6. Arthur E. Farnsley, II. “Thinking of Congregations as Community Assets." Research Notes from the Project on Religion and Urban Culture 1 (1998): 1-5.

7. Ram A. Cnaan. Social and Community Involvement of Religious Congregations Housed in Historic Religious Properties: Findings from a Six-City Study. Philadelphia: School of Social Work, University of Pennsylvania, 1998.

8. Mark Chaves. Religious Organizations and Welfare Reform: Who Will Take Advantage of "Charitable Choice"? Washington: Aspen Institute, 1999.

9. Margaret Harris. “Quiet Care: Welfare Work and Religious Congregations." Journal of Social Policy 24 (1995): 53-71. [CrossRef]

10. Peter Kaldor, John Bellamy, and Sandra Moore. Mission under the Microscope: Keys to Effective and Sustainable Mission. Adelaide: Openbook Publishers, 1995.

11. Peter Kaldor, Robert Dixon, and Ruth Powell. Taking Stock: A Profile of Australian Church Attenders. Adelaide: Open Book Publishers, 1999.

12. Margaret Harris. Organizing God's Work: Challenges for Churches and Synagogues. London: Macmillan, 1998.

13. Ram A. Cnaan, Stephanie C. Boddie, Fermida Handy, Gaynor Yancey, and Richard Schneider. The Invisible Caring Hand: American Congregations and the Provision of Welfare. New York: New York University Press, 2002.

14. Ian A. Bedford. "Reaching Out Beyond Itself: A Framework for Understanding the Community Service Involvement of Local Church Congregations." Ph.D. Thesis, University of Melbourne, Parkville, Australia, 27 January 2004. Available online: https://minerva-access.unimelb.edu.au/handle/11343/38840 (accessed on 23 August 2016).

15. Diana R. Garland, Terry A. Wolfer, and Dennis M. Myers. "How 35 congregations launched and sustained community ministries." Social Work and Christianity 35 (2008): 229-57.

16. F. Ellen Netting, and Mary K. O'Connor. "The Intersectionality of Religion and Social Welfare: Historical Development of Richmond's Nonprofit Health \& Human Services." Religions 2016, forthcoming.

17. Barney G. Glaser, and Anselm L. Strauss. The Discovery of Grounded Theory: Strategies for Qualitative Research. Chicago: Aldine Publishing Co., 1967.

18. Parishioner D, Congregation A, interviewed by the author, 26 March 1999.

19. Parishioner C, Congregation B, interviewed by the author, 11 December 1999.

20. Counsellor C, Congregation B, interviewed by the author, 10 December 1999.

21. Document 2 Congregation $C$ as an internal report drafted February 1992 and provided to the author on 1 July 1999.

22. Jo Anne Schneider. The Kenosha Social Capital Study: Churches, Nonprofits, and Community. Indiana: Indiana University of Pennsylvania, 2001.

23. Mark Lyons, and Ian Nivison-Smith. "Religion and Giving in Australia." The Australian Journal of Social Issues 41 (2006): 419-36.

24. Frank M. Loewenberg. Religion and Social Work Practice in Contemporary American Society. New York: Columbia University Press, 1988.

25. Edward Canda. "Spirituality, Religious Diversity, and Social Work Practice." Social Casework 69 (1988): 238-47.

26. Paul Linossier. A Common Sense of Purpose: The Rejoining Word and Deed. Melbourne: Justice and Social Responsibility Unit, Commission for Mission, Uniting Church in Australia Synod of Victoria, 1994.

27. Uniting Church in Australia. "Uniting Care Network Project Control Group report to June 2016 Synod." Available online: https://www.victas.uca.org.au/aboutus/Synod_Meeting/Reports/C1.3\%20UnitingCare\% 20Network\%20PCG\%20report\%20to\%202016\%20Synod.pdf (accessed on 7 August 2016).

(C) 2016 by the author; licensee MDPI, Basel, Switzerland. This article is an open access article distributed under the terms and conditions of the Creative Commons Attribution (CC-BY) license (http:/ / creativecommons.org/licenses/by/4.0/). 